\title{
In vitro and in vivo isolation of Leishmania tropica from Saudi Arabia
}

\author{
A.A. Mahmoud ${ }^{1}$, A. Al-Tuwaijri ${ }^{2}$, I. Al-Mofleh ${ }^{3}$, and S.A. Al-Khuwaitir ${ }^{4}$ \\ Departments of Pathology ${ }^{1}$, Physiology ${ }^{2}$, Medicine ${ }^{3}$, and Surgery ${ }^{4}$, College of Medicine, \\ King Saud University, Saudi Arabia
}

Z Parasitenkd (1985) 71:271-272

The biochemical typing carried out by Professor W. Peters' laboratory at London School of Hygiene and Tropical Medicine has indicated that the strain we isolated should actually be designated Leishmania major rather than $L$. tropica. 